\title{
Performance Limiting Effects in Power Generation from Salinity Gradients by Pressure Retarded Osmosis
}

\author{
Ngai Yin Yip and Menachem Elimelech* \\ Department of Chemical and Environmental Engineering, Yale University, New Haven, Connecticut 06520-8286, United States \\ Supporting Information
}

ABSTRACT: Pressure retarded osmosis has the potential to utilize the free energy of mixing when fresh river water flows into the sea for clean and renewable power generation. Here, we present a systematic investigation of the performance limiting phenomena in pressure retarded osmosis-external concentration polarization, internal concentration polarization, and reverse draw salt flux —and offer insights on the design criteria of a high performance pressure retarded osmosis power generation system. Thin-film composite polyamide membranes were chemically modified to produce a range of membrane transport properties, and the water and salt permeabilities were characterized to determine the underlying permeability-selectivity tradeoff relationship. We show that power density is constrained by the trade-off between permeability and selectivity of the membrane active layer. This behavior is attributed to the opposing influence of the beneficial effect of membrane water permeability and the detrimental impact of reverse salt flux coupled

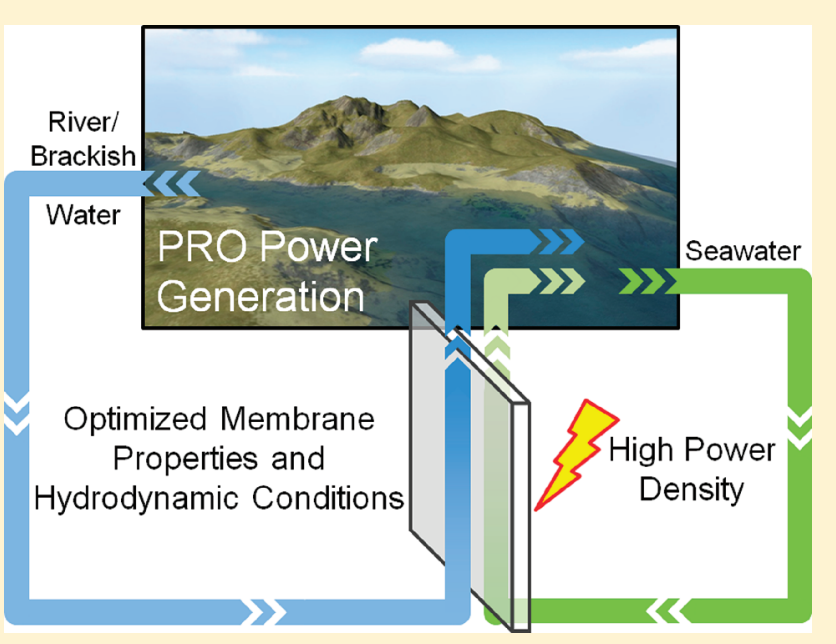
with internal concentration polarization. Our analysis reveals the intricate influence of active and support layer properties on power density and demonstrates that membrane performance is maximized by tailoring the water and salt permeabilities to the structural parameters. An analytical parameter that quantifies the relative influence of each performance limiting phenomena is employed to identify the dominant effect restricting productivity. External concentration polarization is shown to be the main factor limiting performance at high power densities. Enhancement of the hydrodynamic flow conditions in the membrane feed channel reduces external concentration polarization and thus, yields improved power density. However, doing so will also incur additional operating costs due to the accompanying hydraulic pressure loss. This study demonstrates that by thoughtful selection of the membrane properties and hydrodynamic conditions, the detrimental effects that limit productivity in a pressure retarded osmosis power generation process can be methodically minimized to achieve high performance.

\section{INTRODUCTION}

Developing clean and renewable energy sources is one of the greatest global challenges of our time. The continued dependence on fossil fuels to meet our growing energy demands is unsustainable due to its finite availability and the emission of greenhouse gases and air pollutants. Although the advancement of a broad range of alternative energy technologies has increased sustainable production, we still rely substantially on fossil fuels for our current energy consumption. ${ }^{1}$ To realize sustainable energy production for the present and future, intensive research and development is needed to overcome the deficiencies that limit existing alternative energy approaches and produce novel technological options. ${ }^{1}$

Natural salinity gradients have been identified as a potential source of renewable energy. ${ }^{2}$ When two solutions of different concentration are mixed, the Gibbs free energy of mixing is released. The approximately $0.61 \mathrm{kWh}(2.2 \mathrm{MJ})$ of energy dissipated when $1 \mathrm{~m}^{3}$ of fresh river water flows into the sea can potentially be harvested for power production. ${ }^{3}$ A recent study estimates the global renewable energy from natural salinity gradients could reach 2 TW, or $\sim 13 \%$ of the current world energy consumption, if the energy of mixing from all rivers flowing into the ocean was harnessed. ${ }^{3}$

Pressure retarded osmosis (PRO) is one of the methods proposed to tap this source of renewable energy., 4 PRO utilizes the osmotic pressure difference that develops when a semipermeable membrane separates two solutions of different concentration, to drive the permeation of water from the dilute "feed solution" into the more concentrated "draw solution." A hydraulic pressure less than the osmotic pressure difference is applied to the draw solution, thereby "retarding" water flux across the membrane, and a hydroturbine extracts work from the expanding draw

Received: September 12, 2011

Accepted: October 24, 2011

Revised: October 19, 2011

Published: October 24, 2011 
solution volume. PRO can also use anthropogenic waste streams, such as concentrated brine from a desalination plant, ${ }^{6}$ as a draw solution. A closed-loop version of PRO, the osmotic heat engine, uses a thermolytic draw solution of ammonia and carbon dioxide to convert waste thermal energy into useful electrical energy. ${ }^{7}$

Progress in PRO power generation, however, has been hindered by the absence of an adequate membrane. Commercial membranes employed in previous studies did not possess the necessary transport and structural properties, and hence achieved only nominal power densities (power produced per membrane area). ${ }^{8,9}$ A PRO pilot plant in Norway, built to demonstrate power production from natural salinity gradients, generated less than $0.5 \mathrm{~W} / \mathrm{m}^{2}$ using asymmetric cellulose acetate membranes. ${ }^{10}$ This power density is an order of magnitude lower than the power density of $5 \mathrm{~W} / \mathrm{m}^{2}$ required for this specific installation to be commercially viable. ${ }^{11}$ Similarly, previous studies with commercial membranes demonstrated low PRO power densities of $<3.5 \mathrm{~W} / \mathrm{m}^{2}$ using a draw solution with a concentration approximately equal to that of seawater. ${ }^{12}$

Several groups have recently demonstrated membranes capable of high performance in osmotically driven membrane processes. ${ }^{13-17}$ In our previous work, we presented the fabrication of thin-film composite (TFC) membranes customized for high performance in PRO. ${ }^{18}$ The membranes consist of a selective polyamide layer formed by interfacial polymerization on top of a polysulfone support layer made by phase separation. The phase separation fabrication conditions were selected to produce a thin and highly porous support layer that minimizes internal concentration polarization (ICP) and, at the same time, facilitates the formation of an integral polyamide active layer. ${ }^{16}$ The polyamide layer was subjected to a chlorine-alkaline post-treatment in order to tune the water and salt permeabilities. Using a river water feed solution and a seawater draw solution, a power density of $\sim 10.0$ $\mathrm{W} / \mathrm{m}^{2}$ was projected for the prototype PRO-TFC polyamide membrane. The enhanced performance was attributed to the high water permeability of the active layer coupled with a moderate salt permeability and the ability of the support layer to suppress the undesirable accumulation of leaked salt into the porous support. ${ }^{18}$

The fabricated membranes in our earlier study demonstrated the dependence of PRO power density on membrane active and support layer properties. ${ }^{18}$ The permeability-selectivity trade-off that governs separation membranes dictates that a more water permeable membrane is also less selective for salt. ${ }^{19-21}$ Although a membrane active layer with greater water permeability produces a higher water flux and hence, yields a larger power density, the concomitant decline in selectivity causes a simultaneous increase in reverse salt flux. The greater reverse permeation of draw salt, exacerbated by internal concentration polarization in the membrane support layer, gives rise to a reduction in the osmotic driving force across the membrane. ${ }^{18,22}$ The detrimental effect of ICP-coupled reverse salt flux works against the benefit of a more permeable but less selective membrane to restrict PRO performance. ${ }^{18}$ The findings of the paper reveal the convoluted influence of membrane properties on the performance limiting effects and the ensuing power density. As such, an understanding of how membrane properties, as well as other operating parameters, affect water flux and power density is crucial for the design of a high performance PRO system.

In this study we provide a systematic investigation of the detrimental effects of the performance limiting phenomena on PRO power generation from natural salinity gradients. Membranes with a range of transport properties were prepared and evaluated to determine the permeability-selectivity trade-off relationship for thin-film composite polyamide membranes. The influence of membrane properties (specifically, water permeability, salt permeability, and structural parameter) and hydrodynamic conditions on power density performance is analyzed and discussed. We introduce an analytical "Loss Factor" to quantify the dominance of the detrimental effects: external concentration polarization, internal concentration polarization, and reverse salt flux. The role of the membrane properties and hydrodynamic conditions in determining the extent of the performance limiting phenomena is examined to provide insight into their intricate relationship with the resultant power density.

\section{MATERIALS AND METHODS}

Materials and Chemicals. Commercial thin-film composite seawater reverse osmosis membranes (TFC-RO, SW30-HR, Dow Chemical Company, Midland, MI) were acquired for the chlorine-alkaline treatment of the polyamide active layer to produce membranes with a range of water and salt permeabilities. All chemicals used were analytical grade. To prepare the chlorine reagent for membrane modification, sodium hypochlorite aqueous solution (Sigma Aldrich, St. Louis, MO) was added to deionized (DI) water (Milli-Q Millipore, Billerica, MA) and adjusted to $\mathrm{pH} 7.0$ by dosing with $6 \mathrm{M}$ hydrochloric acid. The alkaline reagent for the membrane modification was made by diluting $1 \mathrm{M}$ sodium hydroxide (Fisher Scientific, Pittsburgh, PA) in DI water to the concentration of $0.1 \mathrm{M}$.

Polyamide Active Layer Modification. Exposure of the polyamide active layer to chlorine alters its structure and morphology, resulting in increased water permeability and decreased selectivity (or salt rejection) of the membrane. ${ }^{23-25}$ By carefully controlling the reaction parameters, the water and salt permeabilities of the membrane active layer can be tailored. ${ }^{18,26}$ Different degrees of modification were carried out on the commercial TFCRO membranes in a two-step treatment to produce seven batches of membranes, denoted I through VII, with a range of active layer transport properties. Batch I membranes were not subjected to either treatment step. The membranes of batches II to VII were first immersed in 300, 500,1000,1500, 2000, or 3000 ppm $\mathrm{NaOCl}$ aqueous solution, respectively, for $60 \mathrm{~min}$. In the second step, membrane batches III through VII were transferred to a $0.1 \mathrm{M}$ $\mathrm{NaOH}$ aqueous solution and soaked for $16 \mathrm{~h}$, whereas batch II membranes were left out of this alkaline-treatment step. The treated membranes were then rinsed thoroughly and stored in DI water at $4{ }^{\circ} \mathrm{C}$. Two membranes were prepared in each batch for a total of 14 membrane samples.

Determination of Membrane Water and Salt Permeabilities. Pure water permeability and salt rejection of the modified TFC-RO membranes were evaluated in a laboratory-scale crossflow RO test unit. $^{27}$ The effective membrane area was $20.02 \mathrm{~cm}^{2}$, the crossflow velocity was fixed at $21.4 \mathrm{~cm} / \mathrm{s}$, and spacers were not employed in the feed channel. The loaded membrane was first compacted with DI water at an applied pressure, $\Delta P$, of 31.0 bar ( $450 \mathrm{psi}$ ) until the permeate flux reached a steady state (at least $15 \mathrm{~h}$ ). The applied pressure was then lowered to $27.6 \mathrm{bar}$ (400 psi) and the pure water flux, $J_{\mathrm{w}}$, was calculated by dividing the volumetric permeate rate by the membrane area. Intrinsic water permeability coefficient, $A$, was determined by dividing the water flux by the applied pressure, $A=J_{\mathrm{w}} / \Delta P$. 
Table 1. Summary of Chlorine and Alkaline Treatment Conditions on Commercial TFC Polyamide RO Membrane and the Resultant Water Permeability Coefficient, Salt Rejection, and $\mathrm{NaCl}$ Permeability Coefficient of the Modified Active Layer.

\begin{tabular}{|c|c|c|c|c|c|}
\hline${ }^{a}$ modification & $\mathrm{NaOCl}$ concentration (ppm) & alkaline immersion & $\begin{array}{l}b_{\text {intrinsic water permeability, }} \\
\qquad A\left(\mathrm{~L} \mathrm{~m}^{-2} \mathrm{~h}^{-1} \mathrm{bar}^{-1}\right)\end{array}$ & $\begin{array}{c}{ }^{c} \text { salt rejection, } \\
R(\%)\end{array}$ & $\begin{array}{l}{ }^{d} \text { solute permeability coefficient, } \\
\qquad B\left(\mathrm{~L} \mathrm{~m}^{-2} \mathrm{~h}^{-1}\right)\end{array}$ \\
\hline I. & & no & $1.22 \pm 0.06$ & $99.1 \pm 0.0$ & $0.10 \pm 0.01$ \\
\hline II. & 300 & no & $2.11 \pm 0.28$ & $99.3 \pm 0.2$ & $0.16 \pm 0.10$ \\
\hline III. & 500 & yes & $3.73 \pm 0.55$ & $98.5 \pm 0.6$ & $0.54 \pm 0.08$ \\
\hline IV. & 1000 & yes & $4.37 \pm 0.10$ & $97.6 \pm 0.9$ & $1.11 \pm 0.53$ \\
\hline $\mathrm{V}$. & 1500 & yes & $5.04 \pm 0.07$ & $95.2 \pm 0.8$ & $1.82 \pm 0.42$ \\
\hline VI. & 2000 & yes & $6.71 \pm 0.10$ & $89.3 \pm 0.3$ & $4.99 \pm 0.00$ \\
\hline VII. & 3000 & yes & $7.70 \pm 0.34$ & $86.4 \pm 2.4$ & $7.67 \pm 0.49$ \\
\hline
\end{tabular}

${ }^{a}$ Two samples were modified and characterized for each treatment condition. ${ }^{b}$ Determined by permeate flux measurement in RO tests at 27.6 bar $(400$ psi) with DI water feed at $25{ }^{\circ} \mathrm{C} .{ }^{c}$ Determined by conductivity measurements in RO tests at $27.6 \mathrm{bar}(400 \mathrm{psi})$ with $50 \mathrm{mM}(2920 \mathrm{mg} / \mathrm{L}) \mathrm{NaCl}$ feed solution at $25^{\circ} \mathrm{C}$. ${ }^{d}$ Determined from water flux and salt rejection measurements in RO tests at 27.6 bar $(400 \mathrm{psi})$ with $50 \mathrm{mM}(2920 \mathrm{mg} / \mathrm{L}) \mathrm{NaCl}$ feed solution at $25^{\circ} \mathrm{C}$.

Salt rejection was characterized by keeping the applied pressure at 27.6 bar $(400 \mathrm{psi})$ and measuring rejection of $50 \mathrm{mM} \mathrm{NaCl}$ solution using a calibrated conductivity meter (Oakton Instruments, Vernon Hills, $\mathrm{IL})$. Observed $\mathrm{NaCl}$ rejection, $R$, was determined from the difference in bulk feed $\left(c_{\mathrm{b}}\right)$ and permeate $\left(c_{\mathrm{p}}\right)$ salt concentrations, $R=1-c_{\mathrm{p}} / c_{\mathrm{b}}$. The rejection values for each sample are the average of three different measurements collected over a $\sim 60 \mathrm{~min}$ period. The solute permeability coefficient, $B$, was determined from 28,29

$$
B=J_{\mathrm{w}}\left(\frac{1-R}{R}\right) \exp \left(-\frac{J_{\mathrm{w}}}{k_{\mathrm{f}}}\right)
$$

where $k_{\mathrm{f}}$, the crossflow cell mass transfer coefficient, is calculated from correlations for this geometry. ${ }^{30}$ The temperature of the system was maintained at $25 \pm 0.5^{\circ} \mathrm{C}$ throughout the experiment.

\section{RESULTS AND DISCUSSION}

Membranes are Bounded by Permeability-Selectivity Trade-off. Chlorine-alkaline treatment was carried out on a commercial TFC-SWRO membrane to obtain a range of active layer transport properties. A summary of the intrinsic water permeability coefficient, $A$, salt $(\mathrm{NaCl})$ rejection, $R$, and $\mathrm{NaCl}$ permeability coefficient, $B$, for the resulting membranes is presented in Table 1 . The concentration of the $\mathrm{NaOCl}$ aqueous solution in the chlorination step and the inclusion of a 16-h alkaline immersion step are also indicated in Table 1.

The reactant concentration, solution $\mathrm{pH}$, and exposure times of the chlorine-alkaline treatment were designed to enhance the water permeability of the SWRO polyamide active layer at the expense of some salt rejection capabilities. ${ }^{18,26}$ Although several mechanisms had been proposed to explain the phenomenon, including Orton rearrangement, ${ }^{31}$ direct aromatic ring chlorination, ${ }^{32}$ and increased rotational freedom or flexibility of polymer chains due to the change in hydrogen bonding behavior, ${ }^{24,33}$ the exact mechanism for the change in transport properties of the membrane active layer is not yet fully determined.

Seven batches of membranes, denoted I through VII in Table 1, were subjected to chlorine-alkaline treatments of increasing strength. Batch I membranes were not modified and have the lowest average water permeability coefficient, $A$, of $1.22 \mathrm{~L} \mathrm{~m}^{-2} \mathrm{~h}^{-1}$ bar $^{-1}$ and also the lowest average salt $(\mathrm{NaCl})$ permeability coefficient, $B$, of $0.10 \mathrm{~L} \mathrm{~m}^{-2} \mathrm{~h}^{-1}$. Membranes of batch VII were exposed to the harshest modification treatment (immersion in a $3000 \mathrm{ppm} \mathrm{NaOCl}$ aqueous solution at $\mathrm{pH} 7.0$ for $60 \mathrm{~min}$, followed by a $0.1-\mathrm{M} \mathrm{NaOH}$ soak for $16 \mathrm{~h}$ ) and have the highest average $A$ and $B$ of $7.70 \mathrm{~L} \mathrm{~m}^{-2} \mathrm{~h}^{-1}$ bar $^{-1}$ and $7.67 \mathrm{~L} \mathrm{~m}^{-2} \mathrm{~h}^{-1}$, respectively, among the batches (Table 1). As expected, the average water and salt permeability of the membranes increased from batch I to VII, with increasing strength of chlorine-alkaline treatment. The range of $A$ and $B$ values determined here are consistent with previous studies employing similar modification conditions, ${ }^{18,26}$ and are typical of seawater RO, brackish water RO, and tight nanofiltration membranes. ${ }^{34}$ The salt rejections, $R$, of all the membranes were above $86 \%$ (Table 1 ), verifying the ability of the active layers to retain salt and hence, maintain an osmotic gradient across the membrane in PRO applications.

An inspection of the $A$ and $B$ trend (Table 1 and Figure $S 1$ of the Supporting Information) reveals the permeability-selectivity trade-off that governs TFC polyamide membranes, ${ }^{29,34,35}$ as well as other polymeric membranes, ${ }^{19,21}$ where an increase in water permeability is accompanied by a concomitant increase in salt permeation. For the membranes investigated here, an increase in the water permeability coefficient, $A$, is generally accompanied by an even larger increase in the salt permeability coefficient, $B$. This disproportionate decrease in selectivity is more drastic at higher permeabilities as illustrated in Supporting Information Figure S1. For example, membranes from batch IV have an average $A$ value 3.6 times greater than membranes from batch $\mathrm{I}$, and their average $B$ value is 11.1 times larger. Furthermore, while the average $A$ of membranes from batch VII is 6.3 times that of membranes from batch $I$, the average $B$ is 77 times greater (Table 1 ).

The productivity of conventional SWRO membranes is constrained by the permeability-selectivity trade-off. Specifically, the high selectivity required to produce permeate of low solute concentration in a single-pass RO $\left(>99.3 \%\right.$ salt rejection $\left.{ }^{28}\right)$ puts an upper limit on the permeability of the membrane for seawater desalination. PRO, on the other hand, exploits the controlled mixing of solutions to generate energy and therefore, only needs enough salt rejection to maintain the osmotic driving force. ${ }^{8}$ The constraint of high selectivity is hence partially relaxed for PRO membranes, affording us an additional degree of freedom in customizing the active layer.

Correlation between Membrane Water and Salt Permeabilities. A recent study demonstrated a permeability-selectivity trade-off for salt-rejecting polymeric membranes, ${ }^{35}$ similar to that observed in gas separation membranes. ${ }^{19,20,36}$ Using literature data, an upper bound behavior was observed between the membrane 

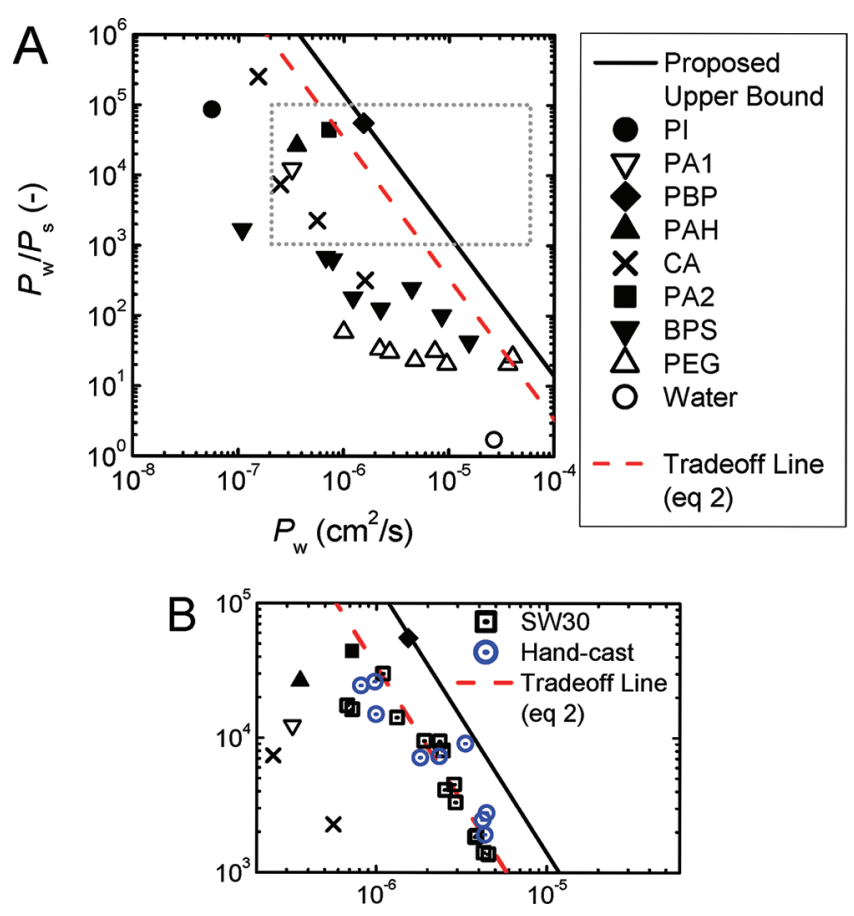

Figure 1. Correlation between water $/ \mathrm{NaCl}$ permeability-selectivity, $P_{\mathrm{W}} / P_{\mathrm{S}}$, and membrane permeability to water, $P_{\mathrm{W}}$. (A) Data from Geise et al. ${ }^{35}$ for various polymeric materials: PI (polyimide), PA1 (aromatic polyamide), PBP (polybenzimidazolepyrrolone), $\mathrm{PAH}$ (polyamidehydrazide), CA (cellulose acetate), PA2 (aromatic polyamide), BPS (sulfonated poly(arylene ether sulfone)), PEG (cross-linked poly(ethylene glycol)), and pure water. The solid black line represents the proposed upper bound relationship ${ }^{35}$ (eq 2 with $\lambda=1.4 \times 10^{-7} \mathrm{~cm}^{4} / \mathrm{s}^{2}$ and $\beta=2)$. Dashed red line $\left(\lambda=0.37 \times 10^{-7} \mathrm{~cm}^{4} / \mathrm{s}^{2}\right.$ and $\left.\beta=2\right)$ indicates the permeability-selectivity trade-off for modified polyamide active layers investigated in this study and our recent publication. ${ }^{18}$ Empirical fitting parameter $\lambda$ was determined by fitting the data to eq 5 and assuming $L=150 \mathrm{~nm}$. (B) Experimental data used to determine the trade-off line (eq 2, dashed red line). Black square symbols represent commercial TFC-SWRO membrane, SW30, modified in this study. Blue circle symbols indicate data for post-treated hand cast PRO membranes reported in our recent publication. ${ }^{18}$

permeability to water, $P_{\mathrm{w}}$, and the water/salt permeability selectivity, $P_{\mathrm{w}} / P_{\mathrm{s}}$ (where $P_{\mathrm{s}}$ is the membrane permeability to salt), and an empirical relationship was proposed: ${ }^{35}$

$$
\frac{P_{\mathrm{w}}}{P_{\mathrm{s}}}=\frac{\lambda}{\left(P_{\mathrm{w}}\right)^{\beta}}
$$

where $\lambda$ and $\beta$ are empirical fitting parameters. The plot of $P_{\mathrm{w}} / P_{\mathrm{s}}$ as a function of $P_{\mathrm{w}}$ in Figure 1A shows the permeability-selectivity trade-off and upper bound behavior.

The membrane permeabilities to water and salt, $P_{\mathrm{w}}$ and $P_{\mathrm{s}}$, respectively, are intrinsic properties of the active layer material, and can be related to the bulk transport properties of the membrane by: ${ }^{35}$

$$
\begin{aligned}
& A=\frac{P_{\mathrm{w}}}{L} \frac{M_{\mathrm{w}}}{R_{\mathrm{g}} T} \\
& B=\frac{P_{\mathrm{s}}}{L}
\end{aligned}
$$

where $A$ is the membrane water permeability coefficient, $L$ is the thickness of the active layer, $M_{\mathrm{w}}$ is the molar mass of water, $R_{\mathrm{g}}$ is the

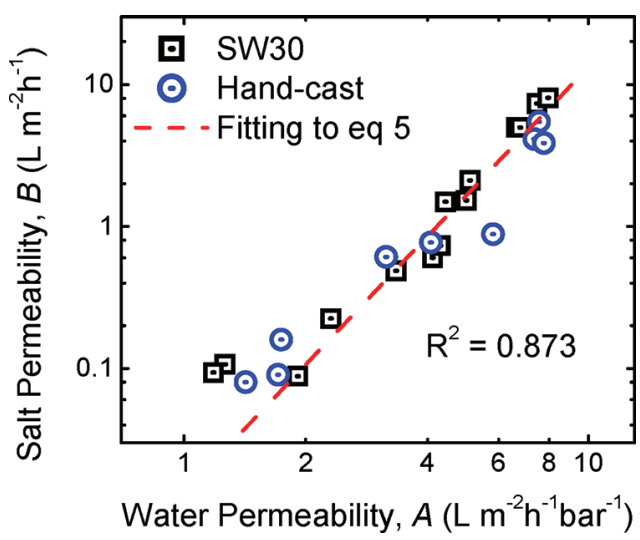

Figure 2. Log-log plot of water and salt permeability coefficients of TFC polyamide membranes subjected to chlorine-alkaline modification. Black square symbols indicate commercial SWRO membranes, SW30, modified in this study. Blue circle symbols indicate data for posttreated hand cast TFC polyamide PRO membranes reported in our recent publication. ${ }^{18} A$ and $B$ data is fitted to eq 5 for $T=298 \mathrm{~K}, M_{\mathrm{w}}=$ $18 \mathrm{~g} / \mathrm{mol}$, and $\beta=2$. Fitting parameter $L^{2} / \lambda$ is determined to be $6.11 \times$ $10^{-3} \mathrm{~s}^{2} / \mathrm{cm}^{2}$.

gas constant, $T$ is the absolute temperature, and $B$ is the membrane salt $(\mathrm{NaCl})$ permeability coefficient. Substitution of eqs 3 and 4 into eq 2 yields an equation linking the water permeability coefficient of the membrane active layer to its salt permeability coefficient through the permeability-selectivity trade-off relationship presented in Figure 1B:

$$
B=\frac{L^{\beta}}{\lambda}\left(\frac{R_{g} T}{M_{\mathrm{w}}}\right)^{\beta+1} A^{\beta+1}
$$

The $A$ and $B$ values determined in this study (Table 1 ), together with the permeability data from our recent publication on hand-cast polyamide PRO membranes, ${ }^{18}$ were fitted to eq 5 with $L^{\beta} / \lambda$ as the empirical fitting parameter. In the gas separation trade-off relationship, the slope of the trade-off line, $\beta$, is proportional to the difference in the squares of the gas molecule diameters. ${ }^{20}$ It is hypothesized that $\beta$ for salt-rejecting membranes takes on a similar fundamental physical meaning, but is currently undetermined. ${ }^{35}$ Therefore, we adopted the value of $\beta=2$ from the permeability-selectivity trade-off study on salt-rejecting polymeric membranes ${ }^{35}$ to perform the fitting.

The experimental data and fitted line are presented in Figure 2, with the water and salt permeability coefficients plotted on a $\log -\log$ scale. For temperature $T=298 \mathrm{~K}$, the fitting parameter $L^{2} / \lambda$ was calculated to be $6.11 \times 10^{-3} \mathrm{~s}^{2} / \mathrm{cm}^{2}$. The plot of $P_{\mathrm{w}} / P_{\mathrm{s}}$ as a function of $P_{\mathrm{w}}$ in Figure 1B shows that the TFC polyamide membranes exhibit the permeability-selectivity trade-off relationship and a similar upper bound behavior (indicated by the dashed red line, $\lambda=0.37 \times 10^{-7} \mathrm{~cm}^{4} / \mathrm{s}^{2}$ ). Due to inherent challenges in the accurate measurement of the effective active layer thickness of a polyamide thin-film composite membrane, the thickness values reported in literature falls over a wide range $(40-300 \mathrm{~nm}) .^{34,35,37}$ As the active layers studied here and in our recent work were modified from seawater reverse osmosis TFC polyamide membranes, an identical polyamide film thickness, $L$, of $150 \mathrm{~nm}$ was assumed to calculate $P_{\mathrm{w}}$ and $P_{\mathrm{s}}$ using eqs 3 and 4 , respectively. The data points generally lie on a slope of $\sim 2$ over 1 order of magnitude in $P_{\mathrm{w}}$. The good agreement between the slope of the experimental results and the assumed value of $\beta=2$ reinforces the hypothesis that 
the slope of the trade-off line represents a yet to be uncovered, fundamental physical principle that governs transport across the active layer. 35

Our recent study demonstrated that in order to maximize PRO performance, the membrane active layer should be highly permeable to water and highly selective to salt. ${ }^{18}$ However, progress toward this ideal situation is limited by the permeability-selectivity trade-off that governs salt-rejecting membranes, as shown above. Thin-film composite polyamide membranes are widely used in separation and purification applications and are considered state-of-the-art technology salt-rejecting membranes. ${ }^{28,29,34,38}$ The empirical relationship between the water and salt permeability coefficient of TFC polyamide membranes (eq 5) developed here can serve as a useful tool in the design of membranes for PRO power generation. In the following subsections, we will demonstrate that by balancing the trade-off between the permeability and selectivity of the membrane active layer, PRO power density performance can be maximized.

Phenomena Governing Water Flux and Power Density in PRO. In osmotically driven membrane processes, the effective osmotic pressure across the membrane less the applied hydraulic pressure, $\Delta \pi_{\mathrm{m}}-\Delta P$, provides the driving force for water flux. In PRO, $\Delta \pi_{\mathrm{m}}$ is lower than the osmotic pressure difference between the bulk draw and feed solutions (i.e., $\Delta \pi_{\mathrm{m}}<\pi_{\mathrm{D}, \mathrm{b}}-\pi_{\mathrm{F}, \mathrm{b}}$ ) due to the detrimental effects of external concentration polarization (ECP) in the draw solution, internal concentration polarization (ICP) within the porous support, and reverse salt flux, $J_{\mathrm{s}}{ }^{\mathrm{R}}$, across the membrane.

In our recent study, we presented the development of a model to predict the water flux in PRO. The model incorporates the performance limiting phenomena of ECP, ICP, and reverse permeation of salt: ${ }^{18}$

$$
\begin{aligned}
J_{\mathrm{w}} & =A\left(\Delta \pi_{m}-\Delta P\right) \\
& =A\left\{\frac{\pi_{D, \mathrm{~b}} \exp \left(-\frac{J_{\mathrm{w}}}{k}\right)-\pi_{\mathrm{F}, \mathrm{b}} \exp \left(\frac{J_{\mathrm{w}} S}{D}\right)}{1+\frac{B}{J_{\mathrm{w}}}\left[\exp \left(\frac{J_{\mathrm{w}} S}{D}\right)-\exp \left(-\frac{J_{\mathrm{w}}}{k}\right)\right]}-\Delta P\right\}
\end{aligned}
$$

where $\pi_{D, \mathrm{~b}}$ and $\pi_{\mathrm{F}, \mathrm{b}}$ are the osmotic pressures of the bulk draw and feed solution, respectively, $k$ is the ECP mass transfer coefficient, $S$ is the structural parameter of the membrane support layer, and $D$ is the diffusion coefficient of the solute. The power density, $W$, defined as the power generated per unit membrane area, can be calculated from:

$$
W=J_{\mathrm{w}} \Delta P
$$

Here, we discuss the detrimental influence of the three performance limiting phenomena-ECP, ICP, and reverse salt flux-on PRO performance. Specifically, the effect of each phenomenon on the salt concentration at the membrane interface (illustrated in Figure S2 of the Supporting Information) is examined and related to the resultant water flux performance. Further discussion on the effect of the three phenomena on the salt concentration profile across the membrane can be found in the Supporting Information.

(a). External Concentration Polarization. As water permeates across the membrane, it dilutes the draw solution and lowers the salt concentration at the active layer, $C_{D, \mathrm{~m}}$, resulting in external concentration polarization at the draw solution side. The reduced osmotic pressure at the solution-membrane

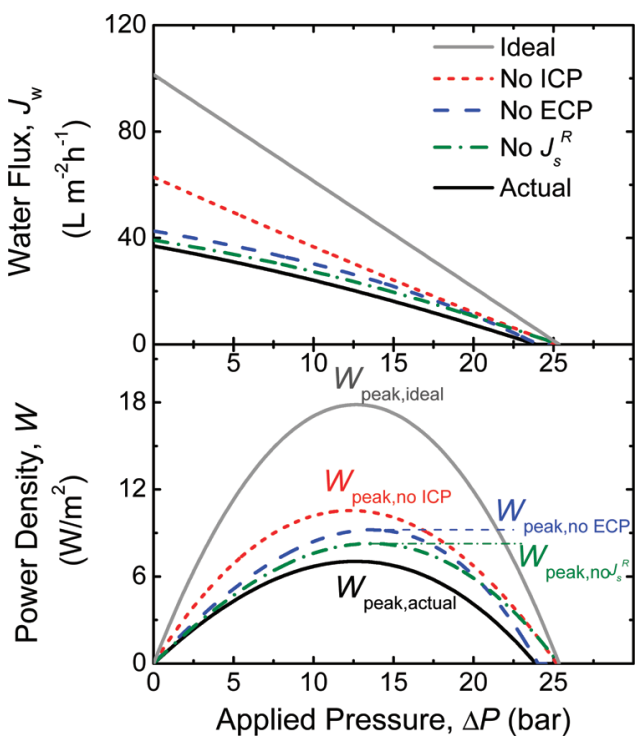

Figure 3. Representative plots of water flux (eq 6) and power density (eq 7) as a function of applied hydraulic pressure. Ideal water flux and power density without any detrimental effects (i.e., $\Delta \pi_{\mathrm{m}}=\pi_{\mathrm{D}, \mathrm{b}}-\pi_{\mathrm{F}, \mathrm{b}}$ ) is indicated by the solid gray line, while the solid black line shows the $J_{\mathrm{w}}$ and $W$ for an actual membrane, incorporating all three performancelimiting effects of ECP, ICP and reverse draw salt flux. The water flux and power density of hypothetical cases where there is no ICP $\left(\right.$ i.e., $\exp \left(J_{w} S / D\right)=$ 1 ), $\operatorname{ECP}\left(\right.$ i.e., $\exp \left(-J_{w} / k\right)=1$ ), or reverse salt flux, $J_{s}^{\mathrm{R}}$, (i.e., $\left.B / J_{\mathrm{w}}\left[\exp \left(J_{\mathrm{w}} \mathrm{S} / \mathrm{D}\right)-\exp \left(-J_{\mathrm{w}} / k\right)\right]=0\right)$ are represented by the dotted red line, dashed blue line, and dot-dashed green line, respectively. $J_{\mathrm{w}}$ and $W$ were calculated using $\pi_{\mathrm{D}, \mathrm{b}}=26.14 \mathrm{bar}, \pi_{\mathrm{F}, \mathrm{b}}=0.789 \mathrm{bar}, A=4.0 \mathrm{~L} \mathrm{~m}^{-2} \mathrm{~h}^{-1}$ $\mathrm{bar}^{-1}, B=0.85 \mathrm{~L} \mathrm{~m}^{-2} \mathrm{~h}^{-1}, S=350 \mu \mathrm{m}$, and $k=38.5 \mu \mathrm{m} / \mathrm{s}(138.6 \mathrm{~L}$ $\left.\mathrm{m}^{-2} \mathrm{~h}^{-1}\right)$.

interface lowers $\Delta \pi_{\mathrm{m}}$ and hence, diminishes the resultant water flux. The effect of dilutive ECP on water flux is reflected in the numerator of the PRO water flux governing equation, eq 6 , where the osmotic pressure of the draw solution is reduced by a factor of $\exp \left(-J_{\mathrm{w}} / k\right)$.

(b). Internal Concentration Polarization. As water permeates across the membrane, the feed solutes are selectively retained by the semipermeable active layer and build up within the porous support. Consequently, the salt concentration at the active-support layer interface, $C_{\mathrm{F}, \mathrm{m}}$, increases. Diffusion works to restore this local concentration to the bulk feed solution concentration, $C_{\mathrm{F}, \mathrm{b}}$, but is hindered by the porous support, which acts as an unstirred boundary layer. The elevated salt concentration within the membrane support layer, termed internal concentration polarization, reduces the effective osmotic pressure across the membrane and therefore, lowers $J_{\mathrm{w}}$. The detrimental effect of concentrative ICP can be seen by examining the PRO water flux equation (eq 6), where the feed solution osmotic pressure $\pi_{\mathrm{F}, \mathrm{b}}$ is magnified by a factor of $\exp \left(J_{\mathrm{w}} S / D\right)$.

(c). Reverse Salt Flux. The deleterious effect of ICP is exacerbated by the reverse flux of draw solute, $J_{s}^{\mathrm{R}}$, whereby the solute permeates from the more concentrated draw solution into the feed solution side. ${ }^{39}$ The leaked solute accumulates in the porous support and further increases the interfacial osmotic pressure, $\pi_{\mathrm{F}, \mathrm{m}}$. This produces an additional reduction of the osmotic driving force and, consequently, a lower water flux. ${ }^{18,22}$ The negative effect of this coupling between reverse salt permeation and ICP is reflected in the denominator of eq 6, where the 
osmotic pressure difference across the membrane is reduced by a factor of $1+B / J_{\mathrm{w}}\left[\exp \left(J_{\mathrm{w}} S / D\right)-\exp \left(-J_{\mathrm{w}} / k\right)\right]$. The reverse flux of draw solute also decreases the interfacial osmotic pressure at the draw side of the membrane. However, the net influence of $J_{s}^{\mathrm{R}}$ on the osmotic pressure difference across the active layer is dominated by the effect in the membrane support layer. This can be validated by applying practical values of $S, D$, and $k$, to the denominator of eq 6 , where the ICP factor, $\exp \left(J_{\mathrm{w}} S / D\right)$, which ranges from 1 to $\infty$, will typically overwhelm the ECP factor, $\exp \left(-J_{\mathrm{w}} / k\right)$, which ranges between zero and one, in the term $\exp \left(J_{\mathrm{w}} S / D\right)-\exp \left(-J_{\mathrm{w}} / k\right)$.

Representative plots of $J_{\mathrm{w}}$ and $W$ as a function of the applied hydraulic pressure, $\Delta P$, are shown in Figure 3. In the ideal case where all three performance limiting phenomena are absent (indicated by the solid gray lines), relatively high PRO water flux (governed by eq 6, $\Delta \pi_{\mathrm{m}}=\pi_{\mathrm{D}, \mathrm{b}}-\pi_{\mathrm{F}, \mathrm{b}}$ ) and power density (eq 7) can theoretically be attained. However, due to the combined detrimental effects of ECP, ICP, and reverse salt flux, the actual $J_{\mathrm{w}}$ and $W$ are much lower than the hypothetical ideal scenario.

To isolate the contribution of each phenomenon to diminishing PRO performance, we consider three hypothetical scenarios where one of the detrimental effects is absent. In Figure 3, the dashed blue lines, dotted red lines, and dot-dashed green lines represent the theoretical cases where there is no external concentration polarization, internal concentration polarization, or reverse salt flux, respectively. The water flux values for these three scenarios are determined using eq 6. For the case of "No ECP", the external concentration polarization factor, $\exp \left(-J_{\mathrm{w}} / k\right)$, is set to unity. To simulate the "No ICP" condition, we apply an internal concentration polarization factor $\exp \left(J_{\mathrm{w}} S / D\right)=1$ to eq 6 . For the third hypothetical case where there is no reverse salt

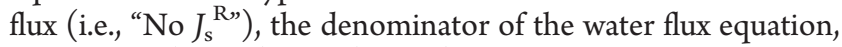
$1+B / J_{\mathrm{w}}\left[\exp \left(J_{\mathrm{w}} S / D\right)-\exp \left(-J_{\mathrm{w}} / k\right)\right]$, is set to unity. Note that by simultaneously fixing the above three factors to unity in eq 6 (i.e., no ECP, ICP, and $J_{s}^{\mathrm{R}}$ ), the ideal water flux and power density (Figure 3, solid gray lines) are recovered.

Removing one of the detrimental effects resulted in higher water flux and power density for the three hypothetical cases than the actual scenario (Figure 3). Therefore, minimizing the detrimental effects of the performance limiting phenomena would enhance PRO performance. This is evident quantitatively in the PRO water flux (eq 6), where $J_{\mathrm{w}}$ can be enhanced by reducing the ICP and reverse salt flux factors, $\exp \left(J_{\mathrm{w}} S / D\right)$ and $1+B / J_{\mathrm{w}}[\exp -$ $\left.\left(J_{\mathrm{w}} S / D\right)-\exp \left(-J_{\mathrm{w}} / k\right)\right]$, respectively, or raising the ECP factor, $\exp \left(-J_{\mathrm{w}} / k\right)$. Understanding the parameters affecting each phenomenon will enable an informed approach to suppress the performance limiting effects and guide in the design of a highperformance PRO system. In the following sections, we will look at the role of the membrane and channel flow condition in determining the extent of the performance limiting phenomena and examine the influence of the parameters on the peak power density.

Influence of Membrane Properties on Peak Power Density. Operating $\mathrm{PRO}$ at a high power density will maximize the utilization of membrane area and reduce capital cost requirements. ${ }^{5,8}$ To achieve peak power density, $W_{\text {peak }}$ a hydraulic pressure that is approximately half of the osmotic pressure difference across the membrane is applied (i.e., $\Delta P \approx\left(\pi_{\mathrm{D}}-\pi_{\mathrm{F}}\right) / 2$, as depicted in Figure 3). Recently, we presented the fabrication of thin-film composite membranes capable of producing high $W_{\text {peak. }}{ }^{18}$ The enhanced performance was attributed to the high water permeability of the active layer, coupled with a moderate salt permeability and the ability of the support layer to suppress the accumulation of

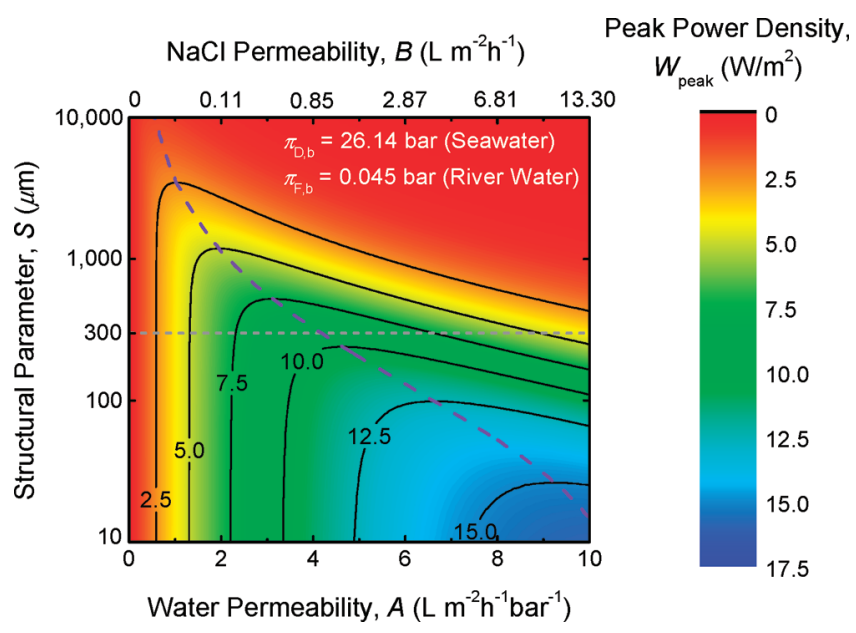

Figure 4. Peak power density, $W_{\text {peak }}$ as a function of active layer water and salt permeabilities (bottom and top horizontal axes, respectively) and support layer structural parameter, $S$ (vertical axis). Dotted horizontal line represents a structural parameter of $300 \mu \mathrm{m}$, while dashed violet line indicates the active layer properties (values of $A$ and $B$ pair), where peak power density is maximized, $W_{\text {peak,max }}$ for a particular $S$. Osmotic pressures of the draw and feed solutions are 26.14 and 0.045 bar, respectively, simulating seawater and river water. ${ }^{18}$ The ECP mass transfer coefficient used in the calculations is $k=38.5 \mu \mathrm{m} / \mathrm{s}\left(138.6 \mathrm{~L} \mathrm{~m}^{-2} \mathrm{~h}^{-1}\right)$.

leaked salt into the porous support. The findings of the study highlighted the important role of membrane transport and structural properties in determining the achievable $W_{\text {peak }}$.

Figure 4 shows a contour plot of the projected $W_{\text {peak }}$ as a function of membrane properties $A, B$, and $S$. The peak power densities were determined by solving $\mathrm{d} W / \mathrm{d} \Delta P=0$ numerically using eqs 6 and 7. Membrane water permeability is represented on a linear scale on the bottom horizontal axis. As the salt permeability is related to $A$ by the trade-off relationship (eq 5), the corresponding $B$ values are indicated on the top horizontal axis (not to scale). The range of $S$ values, indicated on the logscale vertical axis, was chosen to represent the structural parameters of TFC polyamide membranes that are commercially available, SWRO membrane $(\sim 10000 \mu \mathrm{m}),{ }^{17}$ or TFC polyamide membranes that have been demonstrated in a laboratory setting, including hollow fiber membranes $(\sim 600-1400 \mu \mathrm{m}),{ }^{13}$ hand-cast flat sheet membranes $(\sim 300-3000 \mu \mathrm{m}),{ }^{16}$ and nanofiber composite membranes $(\sim 80-110 \mu \mathrm{m}){ }^{14}$ To simulate power generation from natural salinity gradients, the osmotic pressures of the draw and feed solutions were taken to be $\pi_{D, \mathrm{~b}}=$ 26.14 bar and $\pi_{\mathrm{F}, \mathrm{b}}=0.045 \mathrm{bar}$, to represent seawater and river water, respectively. ${ }^{18}$ The mass transfer coefficient in the draw side ECP boundary layer, $k=38.5 \mu \mathrm{m} / \mathrm{s}\left(138.6 \mathrm{~L} \mathrm{~m}^{-2} \mathrm{~h}^{-1}\right)$, was based on the experimental value determined in our previous PRO study. ${ }^{18}$ The corresponding applied hydraulic pressure, $\Delta P$, used to attain the peak power density is shown in Figure $S 3$ of the Supporting Information.

Water flux in PRO is equal to the osmotic driving force, $\Delta \pi_{\mathrm{m}}-$ $\Delta P$, multiplied by the membrane water permeability coefficient, $A$, as stated in eq 6 . As the membrane becomes more permeable to water (i.e., Figure 4, left to right), a corresponding increase in $W_{\text {peak }}$ is observed up to a certain point, after which $W_{\text {peak }}$ decreases instead. The maximum peak power density, $W_{\text {peak,max }}$ that can be attained for a particular structural parameter (indicated by the dashed violet line) occurs at a specific pair of 
water and salt permeabilities. For example, $W_{\text {peak }}$ reaches a maximum of $9.29 \mathrm{~W} / \mathrm{m}^{2}$ for $S=300 \mu \mathrm{m}$ (dotted horizontal line) when $A=4.2 \mathrm{~L} \mathrm{~m}^{-2} \mathrm{~h}^{-1} \mathrm{bar}^{-1}$ and $B=0.99 \mathrm{~L} \mathrm{~m}^{-2} \mathrm{~h}^{-1}$ (intersection with dashed violet line). The drop in $W_{\text {peak }}$ at higher membrane permeabilities is attributed to the limiting effect of reverse draw salt flux - the decreased selectivity of the active layer results in greater passage of draw salt into the membrane support layer, thereby diminishing the osmotic driving force. To the left of the dashed violet line, increasing the water permeability benefits the PRO process as it allows for a higher water flux, and hence, $W_{\text {peak }}$ increases to a maximum value. Beyond that, the detrimental effect of leaked salt accumulated in the porous support overwhelms any gain from a higher $A$. Therefore, PRO power density performance is maximized by balancing the trade-off between the permeability and selectivity of the membrane active layer.

Membranes with a smaller structural parameter achieve maximum $W_{\text {peak }}$ at higher active layer permeabilities, as shown by the dashed violet line sloping toward the bottom right in Figure 4. The performance limiting effect of reverse salt flux is coupled to ICP in the support layer, a membrane with a lower $S$ minimizes the effect of ICP by facilitating the diffusion of leaked draw solute to the bulk solution, thereby mitigating the negative impact of salt buildup at the membrane interface. The dependence of ICPcoupled reverse salt flux on the support layer structural parameter $S$ can be seen by examining the denominator of the PRO water flux equation, $1+B / J_{\mathrm{w}}\left[\exp \left(J_{\mathrm{w}} S / D\right)-\exp \left(-J_{\mathrm{w}} / k\right)\right]$. Structural parameter $S=t_{s} \tau / \varepsilon$, where $t_{\mathrm{s}}$ is the support layer thickness, $\tau$ is the tortuosity, and $\varepsilon$ is the porosity, characterizes the average distance a solute molecule must travel through the support layer when going from the active layer to the bulk feed solution. Membranes with a lower $S$ value are able to tolerate greater increases in $B$ by enabling better mixing of the solution within the porous support, and hence, reduce the ICP factor, $\exp \left(J_{\mathrm{w}} S / D\right)$, to suppress the detrimental effects of salt leakage. This allows the membranes to take greater advantage of more permeable but less selective active layers and achieve a higher $W_{\text {peak,max }}$. Therefore, the optimal combination of active layer permeability and selectivity to achieve the maximum $W_{\text {peak }}$ is determined by the support layer structural parameter.

Conventional TFC reverse osmosis membranes have a thick and dense support layer $(S=10000 \mu \mathrm{m})$ and hence, can only attain a paltry $W_{\text {peak,max }}$ of $1.09 \mathrm{~W} / \mathrm{m}^{2}$, even with an optimal active layer $\left(A=0.6 \mathrm{~L} \mathrm{~m}^{-2} \mathrm{~h}^{-1}\right.$ bar $^{-1}$ and $\left.B=0.003 \mathrm{~L} \mathrm{~m}^{-2} \mathrm{~h}^{-1}\right)$. To meet the target of $5 \mathrm{~W} / \mathrm{m}^{2}$ necessary to produce osmotic power cost-effectively, ${ }^{11}$ the TFC polyamide membrane will need to possess a structural parameter $<1200 \mu \mathrm{m}$, together with balanced active layer transport properties (Figure 4, intersection of $5 \mathrm{~W} / \mathrm{m}^{2}$ contour line and dashed violet line). With an $S$ value of $100 \mu \mathrm{m}$, approximately the lowest structural parameter reported in literature for a TFC membrane, ${ }^{14}$ the projected $W_{\text {peak,max }}$ is $12.5 \mathrm{~W} / \mathrm{m}^{2}$ with a seawater draw solution and river water feed solution. This demonstrates that, while balancing the active layer $A$ and $B$ allows the maximum $W_{\text {peak }}$ to be achieved, the magnitude of $W_{\text {peak,max }}$ is constrained by the support layer structural parameter.

In the development of the PRO water flux equation, the negative effect of concentrative external concentration polarization in the feed solution was considered to be negligible. ${ }^{18}$ However, as the process approaches the operating regime of high water fluxes and low $S$ values, this simplifying assumption may no longer hold true as concentrative ECP exerts a more significant influence on limiting $J_{\mathrm{w}}$ and $W$. As such, although the

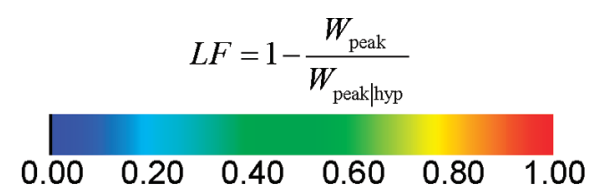

A) External Concentration Polarization $\mathrm{NaCl}$ Permeability, $B\left(\mathrm{~L} \mathrm{~m}^{-2} \mathrm{~h}^{-1}\right)$

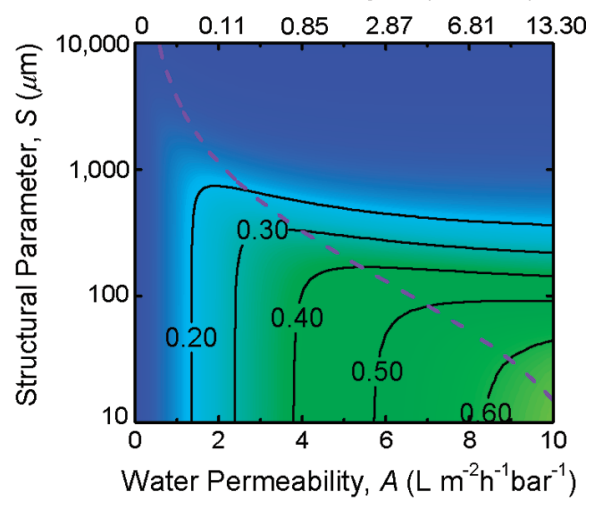

B) Internal Concentration Polarization $\mathrm{NaCl}$ Permeability, $B\left(\mathrm{~L} \mathrm{~m}^{-2} \mathrm{~h}^{-1}\right)$

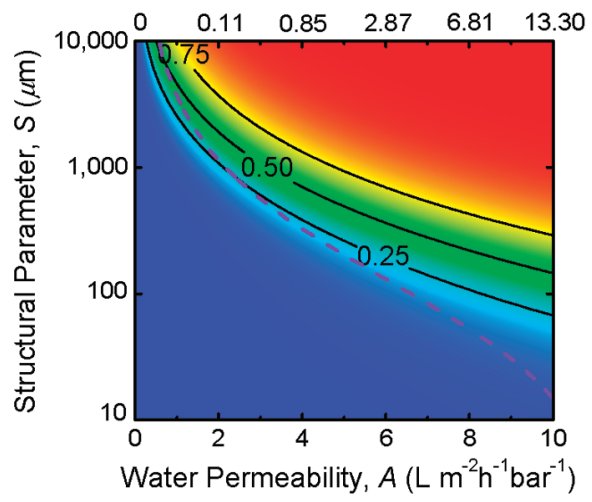

C) Reverse Salt Flux

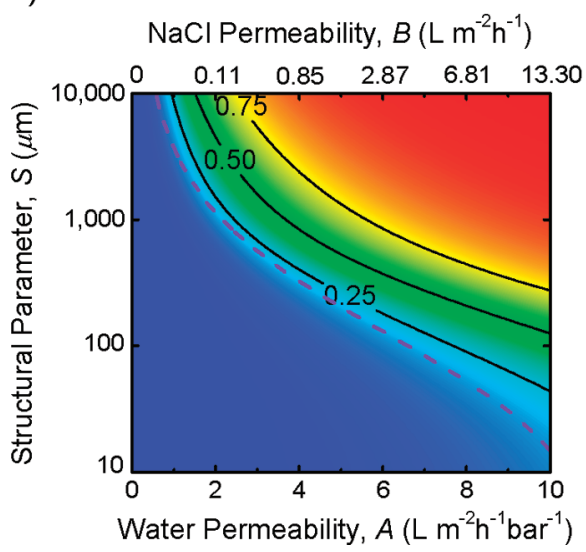

Figure 5. Losses in $W_{\text {peak }}$ due to the individual effect of the performance limiting phenomena: (A) ECP, (B) ICP, and (C) reverse draw salt flux as a function of active layer water and salt permeabilities (bottom and top horizontal axes, respectively), and the support layer structural parameter, $S$ (vertical axis). Scale bar indicates the loss factor, $1-W_{\text {peak }} / W_{\text {peak } \mid \text { hyp }}$ (eq 8). Dashed violet line indicates $W_{\text {peak,max }}$. Osmotic pressures of the draw and feed solution are 26.14 and 0.045 bar, respectively, simulating seawater and river water. ${ }^{18}$ The ECP mass transfer coefficient used in the calculations is $k=38.5 \mu \mathrm{m} / \mathrm{s}(138.6$ $\left.\mathrm{L} \mathrm{m}{ }^{-2} \mathrm{~h}^{-1}\right)$. 
projected $W_{\text {peak,max }}$ for a very thin and highly porous support layer (e.g., $S=50 \mu \mathrm{m}$ ), can reach as high as $14.0 \mathrm{~W} / \mathrm{m}^{2}$, this value is likely to be an overprediction, and a more comprehensive model is needed to reflect the impact of concentrative ECP in the feed side on PRO performance. Furthermore, decreasing the thickness and increasing the porosity of the support layer may compromise the ability of a conventional TFC membrane to withstand hydraulic pressure. Membrane mechanical strength, though beyond the scope of this paper, should be an important factor to consider in the future development of PRO membranes. Lastly, to simplify the PRO water flux and power density predictions, the permeability coefficient of $\mathrm{NaCl}$ salt was used in the model. In an actual PRO process utilizing natural salinity gradients, the draw solution will contain a mixture of ionic species. Therefore, the real power density is likely to deviate slightly from the model predictions.

Losses in Power Density due to Performance Limiting Effects. PRO power density performance is limited by the detrimental effects of ICP, ECP, and reverse salt flux. To isolate the negative contribution of each phenomenon and identify the dominant effect, we consider the hypothetical peak power density, $W_{\text {peak|hyp }}$, of three theoretical scenarios where the effect of one phenomenon is ignored (as described earlier and illustrated in Figure 3). Hence, the difference in the peak power density between the hypothetical and the actual case can be attributed to the phenomenon that was intentionally left out. Dividing this difference by $W_{\text {peak|hyp, we obtain an analytical }}$ parameter that we call the loss factor, LF, which describes the individual influence of ICP, ECP, or reverse draw salt flux on power density performance:

$$
\mathrm{LF}=\frac{W_{\text {peak } \mid \text { hyp }}-W_{\text {peak }}}{W_{\text {peak } \mid \text { hyp }}}=1-\frac{W_{\text {peak }}}{W_{\text {peak } \mid \text { hyp }}}
$$

The loss factors for external concentration polarization $\left(\mathrm{LF}_{\mathrm{ECP}}\right)$, internal concentration polarization $\left(\mathrm{LF}_{\mathrm{ICP}}\right)$, and reverse draw salt flux $\left(\mathrm{LF}_{J_{s}^{R}}\right)$ were calculated for the earlier $W_{\text {peak }}$ analysis (Figure 4) and presented in Figure 5A through $\mathrm{C}$, respectively. The top and bottom horizontal axes represent the water and salt permeability of the active layer, respectively, the vertical axis indicates the support layer structural parameter, and the dashed violet line demarcates $W_{\text {peak,max }}$. To enable comparison between the three phenomena, a common scale bar is adopted. A high loss factor (approaching 1) signifies a greater influence from the effect, while an LF of zero denotes no detrimental impact from the phenomenon. The analytical loss factors provide useful insights into the phenomena limiting performance in $\mathrm{PRO}$ and facilitate a systematic approach to optimize operating parameters for high power density.

Internal concentration polarization and reverse salt flux (Figure 5B and $\mathrm{C}$, respectively) exhibit similar LF trends for the seawaterriver water analysis. This reinforces the coupling between the reverse draw salt flux and ICP, where the leaked solute is hindered by the membrane porous support from mixing with the bulk feed solution. To the left of $W_{\text {peak,max }}$ (dashed violet line), $L_{\text {ICP }}$ and $L_{J_{s}^{R}}$ are less than $\sim 0.25$, while to the right, both loss factors increase sharply to 0.75 and beyond. This observation is consistent with our earlier discussion, stating that at lower $A$ and $B$, the PRO process is able to take advantage of an increase in water permeability to realize a higher $W_{\text {peak }}$ while at higher permeabilities, the adverse effect of ICP-coupled reverse salt flux dominates and hence, negates any potential benefits from a larger $A$.
In actual PRO power generation from salinity gradients, it may be more feasible to utilize input streams of higher salinity as the feed solution, instead of river water with relatively low dissolved solids ( $\sim 80 \mathrm{ppm}$ TDS, $\pi_{\mathrm{F}, \mathrm{b}}=0.045 \mathrm{bar}$ ). The analysis was repeated with a more salty brackish water ( $\sim 5000$ ppm TDS, $\pi_{\mathrm{F}, \mathrm{b}}=3.95$ bar $)$ as the feed solution, and the results are presented in Figure S4 of the Supporting Information. Similar trends in LF were generally observed when a more saline feed solution was employed, with the exception of the loss factor for ICP. Compared to river water feed solution, $\mathrm{LF}_{\mathrm{ICP}}$ was higher at large structural parameters when brackish water was used as the feed solution, signifying a more influential role played by internal concentration polarization.

As water permeates across the membrane, the feed solutes are selectively retained and concentrate within the porous support layer. Hence, the osmotic pressure at the active layer interface is the bulk osmotic pressure of the feed solution multiplied by the ICP factor $-\pi_{\mathrm{F}, \mathrm{b}} \exp \left(J_{\mathrm{w}} S / D\right)$. Use of a very dilute feed solution reduces the interfacial concentration, thus mitigating the detrimental effect of concentrative ICP. However, when the feed solution contains more salt, internal concentration polarization amplifies the larger $\pi_{\mathrm{F}, \mathrm{b}}$, resulting in a considerably higher interfacial osmotic pressure at the feed side. Thus, the driving force for water flux, $\Delta \pi_{\mathrm{m}}$, is drastically lowered, and PRO performance is diminished. The ICP factor, $\exp \left(J_{w} S / D\right)$, increases exponentially with $S$. Therefore, a minimized membrane support layer structural parameter is vital to achieve high power density with saline feed solutions.

A comparison of Figure 4 with Figure 5A shows that the loss factor for external concentration polarization displays a roughly inverse trend to the power density. The extent of ECP is determined by the water flux across the membrane-water permeation dilutes the draw solution at the membrane and hence, reduces the interfacial osmotic pressure. As power density, $W$, is $J_{\mathrm{w}}$ multiplied by the applied hydraulic pressure, $\Delta P$ (eq 7), ECP will therefore be more adverse at higher power densities. At large water fluxes and low $S$ values (i.e., bottom right quadrant of Figure $5 \mathrm{~A}$ ), $\mathrm{LF}_{\mathrm{ECP}}$ escalates to $>0.40$, suggesting that ECP is the key phenomenon limiting PRO performance at high $W$. As such, after the membrane transport and structural properties are optimized, the PRO power density performance can be further enhanced by inducing favorable hydrodynamic flow conditions in the draw solution channel to minimize ECP.

Influence of Hydrodynamic Conditions on Peak Power Density. As water permeates across the membrane, the osmotic driving force is reduced due to dilutive external concentration polarization. The extent of ECP is determined by the mass transfer coefficient, $k$, in the boundary layer. By improving the mixing at the membrane-solution interface through increased crossflow velocity or the use of spacers, the mass transfer coefficient can be enhanced. The detrimental effect of the ECP factor, $\exp \left(-J_{\mathrm{w}} / k\right)$, in eq 6 is reduced by the higher $k$ value, thus increasing the PRO peak power density performance.

Figure 6 shows the projected $W_{\text {peak,max }}$ (dashed violet line, left vertical axis) as a function of the mass transfer coefficient. The maximum peak power densities were determined numerically using eqs 5,6 , and 7 , and by simultaneously solving for the conditions for peak $W$ (i.e., $\mathrm{d} W / \mathrm{d} \Delta P=0$ ) and maximum $W_{\text {peak }}$ (i.e., $\mathrm{d} W_{\text {peak }} / \mathrm{d} A=0$ ). The corresponding water permeability coefficient, $A$, required to maximize the peak power density is indicated by the solid blue line (right vertical axis). A seawater draw solution $\left(\pi_{\mathrm{D}, \mathrm{b}}=26.14\right.$ bar $)$ and a river water feed solution $\left(\pi_{\mathrm{F}, \mathrm{b}}=0.045 \mathrm{bar}\right)$ were used to simulate power generation from 


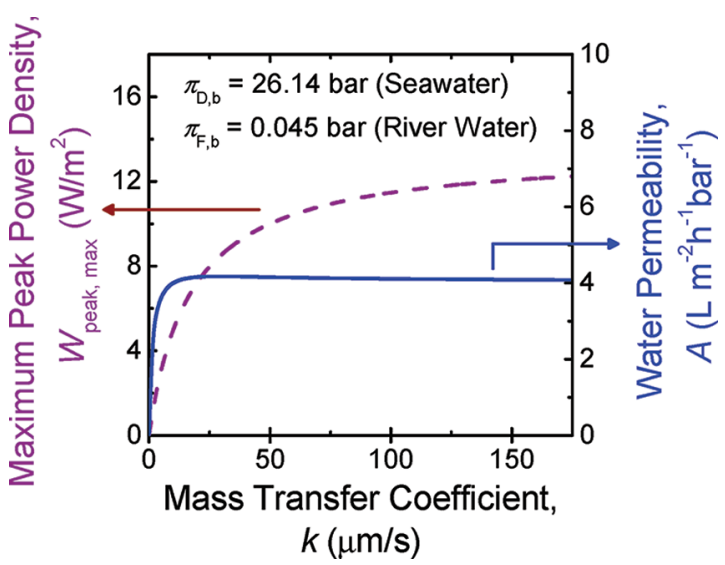

Figure 6. Maximum peak power density achievable, $W_{\text {peak,max }}$ (dashed violet line), as a function of mass transfer coefficient, $k$, in the ECP boundary layer. The corresponding membrane water permeability, $A$, to achieve this maximum peak power density is indicated by the solid blue line. Membrane porous support structural parameter, $S$ was assigned a value of $300 \mu \mathrm{m}$. Osmotic pressure of the draw and feed solutions is 26.14 and 0.045 bar, respectively, to simulate seawater and river water. ${ }^{18}$

natural salinity gradients. The structural parameter $(S=300 \mu \mathrm{m})$ represents a high performance support layer fabricated by the phase inversion technique employed in the manufacture of conventional TFC membrane. ${ }^{16}$

When the mass transfer coefficient is low, dilutive ECP is significant and PRO power density is low. An increase in $k$ quickly eliminates this inefficiency, translating to rapid gains in $W_{\text {peak,max }}$ as indicated by the initial steep slope of the dashed violet line. At high $J_{w}$, the enhancement in peak power performance diminishes with increasing $k$, and gradually levels off after $W_{\text {peak,max }}>12 \mathrm{~W} / \mathrm{m}^{2}$. This behavior is attributed to (i) the growing influence of the other two performance limiting phenomena, ICP and reverse salt flux; and (ii) the increased dilutive ECP effect at greater water fluxes, as indicated by $J_{\mathrm{w}}$ in the ECP factor, $\exp \left(-J_{\mathrm{w}} / k\right)$. While enhancing the hydrodynamic conditions in the draw side of the membrane channel can increase the power density performance, it would also raise the parasitic hydraulic losses and impose additional pumping cost to the PRO process. Hence, any power density improvements from a higher $k$ would only be worthwhile if they can offset the hydraulic losses to achieve a net gain in overall productivity. Analysis of the relationship between $W_{\text {peak,max }}$ and $k$, such as the one presented in Figure 6, can help guide the design of a cost-efficient PRO system. We note that the balanced water permeability coefficient required to maximize peak power density (i.e., $\mathrm{d} W_{\text {peak }} / \mathrm{d} A=0$ ) is essentially independent of the hydrodynamic conditions for $k>$ $5 \mu \mathrm{m} / \mathrm{s}$, as indicated by the flat portion of the solid blue line.

Implications for Renewable Energy from Salinity Gradients. To realize sustainable power generation with natural salinity gradients, the cost-efficiency of PRO and other competing technologies needs to be enhanced. This study demonstrates that the performance of a PRO power generation process can be methodically improved through thoughtful selection of the membrane properties and hydrodynamic conditions to purposefully minimize the performance limiting effects. At the heart of PRO power generation is the semipermeable membrane, and thus, the productivity of the process is circumscribed by the membrane properties. Further substantial improvements in performance necessitate membrane development to depart from the conventional thin-film composite polyamide membranes that are currently considered state-of-the-art technology. ${ }^{38,40} \mathrm{Ex}$ amples of next-generation PRO membranes envisioned include self-supporting selective layers that eliminate ICP by doing away with the need for a porous layer and novel membrane materials with superior transport properties that can shift the permeability-selectivity upper bound further outward.

\section{ASSOCIATED CONTENT}

Supporting Information. Discussion on the influence of external concentration polarization, internal concentration polarization, and reverse salt flux on membrane salt concentration profile; plot of water and salt permeabilities of TFC polyamide membranes subjected to chlorine-alkaline modification (Figure S1); schematic representation of the salt concentration profile across a thin-film composite membrane in PRO configuration (Figure S2); contour plot of applied hydraulic pressure required to achieve peak power density as a function of active layer water and salt permeabilities and support layer structural parameter (Figure S3); peak power density as a function of active layer water and salt permeabilities and support layer structural parameter, and losses in peak power density due to the individual effect of the performance limiting phenomena of ECP, ICP, and reverse draw salt flux (Figure S4A-D). This material is available free of charge via the Internet at http://pubs.acs.org.

\section{AUTHOR INFORMATION}

\section{Corresponding Author}

*Phone: (203) 432-2789; e-mail: menachem.elimelech@yale.edu.

\section{ACKNOWLEDGMENT}

This publication is based on work supported in part by Award No. KUS-C1-018-02, made by King Abdullah University of Science and Technology (KAUST); the WaterCAMPWS, a Science and Technology Center of Advanced Materials for the Purification of Water with Systems under the National Science Foundation Grant CTS-0120978; and Oasys Water Inc. We also acknowledge the Graduate Fellowship (to Ngai Yin Yip) made by the Environment and Water Industrial Development Council of Singapore.

\section{REFERENCES}

(1) Hoffert, M. I.; Caldeira, K.; Benford, G.; Criswell, D. R.; Green, C.; Herzog, H.; Jain, A. K.; Kheshgi, H. S.; Lackner, K. S.; Lewis, J. S.; Lightfoot, H. D.; Manheimer, W.; Mankins, J. C.; Mauel, M. E.; Perkins, L. J.; Schlesinger, M. E.; Volk, T.; Wigley, T. M. L. Advanced technology paths to global climate stability: Energy for a greenhouse planet. Science 2002, 298 (5595), 981-987.

(2) Pattle, R. E. Production of electric power by mixing fresh and salt water in the hydroelectric pile. Nature 1954, 174 (4431), 660-660.

(3) La Mantia, F.; Cui, Y.; Pasta, M.; Deshazer, H. D.; Logan, B. E. Batteries for efficient energy extraction from a water salinity difference. Nano Lett. 2011, 11 (4), 1810-1813.

(4) Loeb, S. Osmotic power-plants. Science 1975, 189 (4203), 654-655.

(5) Ramon, G. Z.; Feinberg, B. J.; Hoek, E. M. V. Membrane-based production of salinity-gradient power. Energy Environ. Sci. 2011, 4, 4423-4434. 
(6) Loeb, S. Production of energy from concentrated brines by pressure-retarded : I. Preliminary technical and economic correlations. J. Membr. Sci. 1976, 1 (1), 49-63.

(7) McGinnis, R. L.; McCutcheon, J. R.; Elimelech, M. A novel ammonia-carbon dioxide osmotic heat engine for power generation. J. Membr. Sci. 2007, 305 (1-2), 13-19.

(8) Lee, K. L.; Baker, R. W.; Lonsdale, H. K. Membranes for powergeneration by pressure-retarded osmosis. J. Membr. Sci. 1981, 8 (2), $141-171$.

(9) Achilli, A.; Cath, T. Y.; Childress, A. E. Power generation with pressure retarded osmosis: An experimental and theoretical investigation. J. Membr. Sci. 2009, 343 (1-2), 42-52.

(10) Brekke, G. The Statkraft Prototype Plant. http://osmosissummit.event123.no/programsummit2010.cfm (accessed).

(11) Skilhagen, S. E. Osmotic power-A new, renewable energy source. Desalin. Water Treat. 2010, 15 (1-3), 271-278.

(12) Achilli, A.; Childress, A. E. Pressure retarded osmosis: From the vision of Sidney Loeb to the first prototype installation-Review. Desalination 2010, 261 (3), 205-211.

(13) Wang, R.; Shi, L.; Tang, C. Y. Y.; Chou, S. R.; Qiu, C.; Fane, A. G. Characterization of novel forward osmosis hollow fiber membranes. J. Membr. Sci. 2010, 355 (1-2), 158-167.

(14) Song, X. X.; Liu, Z. Y.; Sun, D. D. Nano gives the answer: Breaking the bottleneck of internal concentration polarization with a nanofiber composite forward osmosis membrane for a high water production rate. Adv. Mater. 2011, 23 (29), 3256-3260.

(15) Yang, Q.; Wang, K. Y.; Chung, T. S. Dual-layer hollow fibers with enhanced flux as novel forward osmosis membranes for water production. Environ. Sci. Technol. 2009, 43 (8), 2800-2805.

(16) Tiraferri, A.; Yip, N. Y.; Phillip, W. A.; Schiffman, J. D.; Elimelech, M. Relating performance of thin-film composite forward osmosis membranes to support layer formation and structure. J. Membr. Sci. 2011, 367 (1-2), 340-352.

(17) Yip, N. Y.; Tiraferri, A.; Phillip, W. A.; Schiffman, J. D.; Elimelech, $M$. High performance thin-film composite forward osmosis membrane. Environ. Sci. Technol. 2010, 44 (10), 3812-3818.

(18) Yip, N. Y.; Tiraferri, A.; Phillip, W. A.; Schiffrnan, J. D.; Hoover, L. A.; Kim, Y. C.; Elimelech, M. Thin-film composite pressure retarded osmosis membranes for sustainable power generation from salinity gradients. Environ. Sci. Technol. 2011, 45 (10), 4360-4369.

(19) Robeson, L. M. Correlation of separation factor versus permeability for polymeric membranes. J. Membr. Sci. 1991, 62 (2), 165-185.

(20) Freeman, B. D. Basis of permeability/selectivity tradeoff relations in polymeric gas separation membranes. Macromolecules 1999, 32 (2), 375-380.

(21) Mehta, A.; Zydney, A. L. Permeability and selectivity analysis for ultrafiltration membranes. J. Membr. Sci. 2005, 249 (1-2), 245-249.

(22) Wei, J.; Liu, X.; Qiu, C. Q.; Wang, R.; Tang, C. Y. Y. Influence of monomer concentrations on the performance of polyamide-based thin film composite forward osmosis membranes. J. Membr. Sci. 2011, 381 (1-2), 110-117.

(23) Glater, J.; Zachariah, M. R.; Mccray, S. B.; Mccutchan, J. W. Reverse-osmosis membrane sensitivity to ozone and halogen disinfectants. Desalination 1983, 48 (1), 1-16.

(24) Kwon, Y. N.; Leckie, J. O. Hypochlorite degradation of crosslinked polyamide membranes-II. Changes in hydrogen bonding behavior and performance. J. Membr. Sci. 2006, 282 (1-2), 456-464.

(25) Glater, J.; Hong, S. K.; Elimelech, M. The search for a chlorineresistant reverse-osmosis membrane. Desalination 1994, 95 (3), $325-345$.

(26) Jons, S. D.; Stutts, K. J.; Ferritto, M. S. Mickols, W. E. Treatment of composite polyamide membrane to improve performance. Patent 5876602,1999

(27) Ang, W. S.; Elimelech, M. Protein (BSA) fouling of reverse osmosis membranes: Implications for wastewater reclamation. J. Membr. Sci. 2007, 296 (1-2), 83-92.

(28) Baker, R. W., Membrane Technology and Applications, 2nd ed.; J. Wiley: New York, 2004; p 538.
(29) Mulder, M. Basic Principles of Membrane Technology, 2nd ed.; Kluwer Academic: Boston, 1996; p 564.

(30) Hoek, E. M. V.; Kim, A. S.; Elimelech, M. Influence of crossflow membrane filter geometry and shear rate on colloidal fouling in reverse osmosis and nanofiltration separations. Environ. Eng. Sci. 2002, 19 (6), 357-372.

(31) Kawaguchi, T.; Tamura, H. Chlorine-resistant membrane for reverse-osmosis. I. Correlation between chemical structures and chlorine resistance of polyamides. J. Appl. Polym. Sci. 1984, 29 (11), 3359-3367.

(32) Glater, J.; Zachariah, M. R. A mechanistic study of halogen interaction with polyamide reverse-osmosis membranes. ACS Symp. Ser. 1985, 281, 345-358.

(33) Kwon, Y. N.; Tang, C. Y.; Leckie, J. O. Change of chemical composition and hydrogen bonding behavior due to chlorination of crosslinked polyamide membranes. J. Appl. Polym. Sci. 2008, 108 (4), 2061-2066.

(34) Petersen, R. J. Composite reverse-osmosis and nanofiltration membranes. J. Membr. Sci. 1993, 83 (1), 81-150.

(35) Geise, G. M.; Park, H. B.; Sagle, A. C.; Freeman, B. D.; McGrath, J. E. Water permeability and water/salt selectivity tradeoff in polymers for desalination. J. Membr. Sci. 2011, 369 (1-2), 130-138.

(36) Robeson, L. M.; Freeman, B. D.; Paul, D. R.; Rowe, B. W. An empirical correlation of gas permeability and permselectivity in polymers and its theoretical basis. J. Membr. Sci. 2009, 341 (1-2), 178-185.

(37) Freger, V. Nanoscale heterogeneity of polyamide membranes formed by interfacial polymerization. Langmuir 2003, 19 (11), 47914797.

(38) Elimelech, M.; Phillip, W. A. The future of seawater desalination: Energy, technology, and the environment. Science 2011, 333 (6043), 712-717.

(39) Phillip, W. A.; Yong, J. S.; Elimelech, M. Reverse draw solute permeation in forward osmosis: Modeling and experiments. Environ. Sci. Technol. 2010, 44 (13), 5170-5176.

(40) Lee, K. P.; Arnot, T. C.; Mattia, D. A review of reverse osmosis membrane materials for desalination- $\neq$ Development to date and future potential. J. Membr. Sci. 2011, 370 (1-2), 1-22. 